\title{
Video Résumés Portrayed: Findings and Challenges
}

\author{
Annemarie M. F. Hiemstra
}

Erasmus University Rotterdam, the Netherlands

Eva Derous

Ghent University, Belgium

In: I. Nikolaou and J. Oostrom (Eds.). Employee Recruitment, Selection, and Assessment: Contemporary issues for theory and practice. Sussex, UK: Psychology Press.. 


\title{
CHAPTER VIDEO RÉSUMÉS
}

\begin{abstract}
Recent technological developments and the increased use of internet-based applications have resulted in the emergence of so-called video résumés. This chapter first presents the characteristics of video résumés as a selection instrument by comparing the instrument with other, related selection tools, like the job interview. The chapter proceeds with a review of existing research on video résumés and ends with an agenda for future research.
\end{abstract}




\section{CHAPTER VIDEO RÉSUMÉS}

\section{Introduction}

The introduction of personal computers in the nineteen eighties marked the onset of developments in computerized testing (Oostrom, 2010; Sands, Waters, \& McBride, 1997). In the nineteen nineties the use of internet started to spread. This development and the technological advancements in personal computers opened to door to the use of multimedia in selection procedures (Oostrom, 2010), such as video résumés (Doyle, 2010; Hiemstra, Derous, Serlie, \& Born, 2012; Gissel, Thompson, \& Pond, 2013). Video résumés have been described as short video-taped messages in which applicants present themselves to potential employers on requested knowledge, skills, abilities, and other characteristics, such as motivation and career objectives (Hiemstra et al., 2012). Typically, video résumés are uploaded to the internet for potential employers to review (Doyle, 2010). Although the format of video résumés can vary (e.g., structure, multimedia usage), the common denominator is that auditory and visual information of the applicant is introduced in a short video clip (about 1 to 2 minutes), during the earliest screening phase, and in an asynchronous manner (i.e., the employer views the application at a later point in time). These characteristics differentiate the video résumé from a real-time, video-supported interview (e.g., via Skype).

Résumés are widely used for initial screening, but still little is known about new résumé formats, like video résumés. With the increased use of multimedia applications, such as video résumés, questions arise on their validity, fairness and acceptability. This chapter describes the characteristics of video résumés, followed by a review on what is currently known about video résumés and an agenda for future research. The next paragraph describes the characteristics of video résumés by means of a comparison with job interviews, being another popular and widely used screening method. Résumé-screening and interview-screening are typically considered as 


\section{CHAPTER VIDEO RÉSUMÉS}

two different selection tools that are discussed separately in the literature (e.g., Guion, 2011). Multimedia applications, like the opportunity to post videotaped résumés on the internet, may have altered the nature of résumé-screening and may have made résumé -screening in some aspects more comparable to face-to-face job interviews. Findings from the interview literature can help improve our understanding of the benefits and disadvantages of video résumés as a selection tool. Although video résumés and job interviews share some characteristics, they are not simply exchangeable. We aim to set the stage here by explaining the similarities and differences between video résumés and job interviews, thereby defining the video résumé as a selection instrument.

\section{Setting the stage: Characteristics of video résumés vis-à-vis job interviews}

Arthur and Villado (2008) argue that one should distinguish comparisons made between predictor constructs (e.g., personality versus cognitive ability) from comparisons made between predictor methods (e.g., video résumés versus job interviews). This chapter focuses on the latter. However, without a clear construct-oriented approach, selection tools may be used in a rather intuitive way. For instance, interviews may merely serve the purpose of checking whether there is a 'click' between interviewer and interviewee. Without a clear construct-oriented approach, video résumés may also result in invalid impression about job candidates. Critics may add that a construct-oriented approach is not feasible for video résumés, contrary to structured interviews. After all, video résumés are self-presentational in nature, like paper résumés. But this can be refuted in the sense that requirements can be set by the hiring organization on the contents of the video résumé. We believe that the validity and reliability of constructs measured by video résumés can be improved in the same way that the validity and reliability of interviews can be 


\section{CHAPTER VIDEO RÉSUMÉS}

improved: Through various ways of structuration of the content and the raters' evaluation of the applicant (Campion, Palmer, \& Campion, 1997).

Having said that about the importance of distinguishing between constructs and methods, five comparable aspects are put forward here to compare video résumés and interviews as two methods for selection. Video résumés and job interviews can both be considered as general denominators for tools that vary in their goal and content (type of information exchanged), format (kind of communication code, administration duration, number of actors involved, direction of communication, degree of surveillance), standardization/structure (whether standardized procedures are maintained across applicants and whether tools are structured), administration medium (whether the information carrier is analogues or digital in nature), and interactivity (whether the tool allows for reciprocal information exchange and is (a)synchronous in nature). Next, we will investigate these five basic features of tools for the video résumé, followed by the job interview. This chapter will not present an in-depth analysis of interview characteristics (the interested reader can find recent, more extensive reviews in Dipboye \& Johnson, 2013; Levashina, Hartwell, Morgeson, \& Campion, 2013; Macan, 2009). Instead, we will discuss the five, abovementioned characteristics to compare video résumés to job interviews, thereby defining video résumés.

First, the goal and content of video résumés is to present personal information to potential employers. Video résumés typically include important educational and professional background information such as academic background, work experience, and extracurricular activities, comparable to paper résumés (Cole, Rubin, Feild, \& Giles, 2007; Hiemstra et al., 2012). In addition to bio data information, one's motivation to apply can be elucidated and relevant skills and knowledge can be presented, like software skills or communication skills. 


\section{CHAPTER VIDEO RÉSUMÉS}

This information can be presented either in a generic form (such as a résumé that is posted on a recruitment website), or can be tailored to fit a specific job profile that highlights specific skills as requested by the hiring organization (e.g., a résumé for a specific job).

Second, video résumés may vary widely in format characteristics because of new opportunities that arise with the use of multimedia. The format of video résumés may range from verbal description of skills and accomplishments to a format in which a predefined set of questions are answered and/or requested work samples that demonstrate job relevant skills (e.g., for a ballet audition; Hamilton, 1998). Although there is no golden standard as to the length of the video résumé, video résumés are typically very short ( i.e., lasting about one to two minutes; like an ' elevator pitch').

Third, standardization, or the degree that standardized procedures are maintained across all applicants/video résumés, may differ considerably. For instance, employers may offer applicants a free choice to use video résumés or not when applying. Additionally, employers may use a highly structured approach when they request all applicants to apply with a video résumé. That is, the video résumé format can be more or less structured depending on whether applicants have to present specific information that is job related (Guion, 2011). That is, the video résumé format can be more or less structured depending on whether applicants have to present the same type and amount of job related information to potential employers and whether employers use a scoring protocol and numerical rating scales to evaluate video résumés, just like the structured interview (Campion et al., 1997; Guion, 2011). For instance, to apply for the YouTube Symphony Orchestra, musicians were requested by the YouTube organization and the London Symphony Orchestra, to perform several preset audition pieces in a video résumé. Therefore, a structured video résumé will usually be standardized but the reverse is not necessarily the case. 


\section{CHAPTER VIDEO RÉSUMÉS}

As mentioned, when content requirements are lacking, the self-presentational nature of video résumés as initiated by the job applicant may result in a high variation of the amount, type and degree of job relevant information (Gissel et al., 2013). As with the individualized structured interview, the structure of video résumés might be unique for each candidate, specifically so when initiated by the job applicant. Thus, the use of video résumés can be standardized (e.g., when all applicants use video résumés) but unstructured (i.e., when some video résumés target the job requirements more than others). However, when employers request applicants to present certain job-related skills in the video résumé (as for the YouTube Symphony Orchestra), the video résumés will be highly structured and standardized.

Fourth, the administration medium of video résumés is digital (e.g., web-based) whereas interviews can be both face-to-face, via phone or via the internet. Finally, and as consequence, the interactivity of video résumés is limited, meaning that the pace of feedback exchange is rather low. Video résumés are posted and can be consulted at anytime from anywhere. Furthermore, communication is one-way directed (from the applicant to the recruiter). Other than with interviews or instant messaging through the internet, video-résumés are thus a-synchronous in nature.

As will be further illustrated, job interviews may vary along the five aspects that were discussed here for video résumés. First, the content of job interviews may depend on the particular goal of the interview. Overall, four goals are distinguished in job interviews: information exchange between interviewer and interviewee, assessment of interviewees by interviewers, establishing personal contact between interviewers and interviewees, and providing a realistic job preview to interviewees (Lievens, 2011). That is, the interview allows interviewers to retrieve information about applicants' competencies in order to assess person-job fit. This 


\section{CHAPTER VIDEO RÉSUMÉS}

face-to-face (or synchronous) encounter also allows interviewers to present the job and organization as well as to establish a relationship with the applicant (Dipboye \& Johnson, 2013), which is not the case in video résumé applications. Second, the interview format is determined by factors such as interview duration, number of interviewers, or applied interview medium (e.g., videoconferencing or telephone interview). Third, the interview typically consists of three stages namely a rapport building, information exchange, and evaluation stage. The degree of standardization and structuration are largely determined by the level of structure in interview questions and evaluation forms, ranging from unstructured to highly structured (e.g., behavioral interviews), as well as the use of standard procedures across all interviews (see Table 1). Further, the administration medium of the classical face-to-face interview is analogues in nature, but current technological developments and globalization have opened the door to telephone and web based interviews (Bauer, Truxillo, Paronto, \& Weekley, 2004; Dipboye \& Johnson, 2013). Finally, as mentioned above, the interactivity in interviews is high as they are synchronous in nature, unlike video résumés. The duration of interviews is also much longer than video résumés (with a typical interview lasting about 30 minutes; e.g., Dipboye \& Johnson, 2013), thus allowing for more interaction between the applicant and the recruiter.

At least two facets make video-résumés resemble the traditional interview. First, much like the traditional job interview, video résumés enable to transmit more dynamic information, including both visual/non-verbal and auditory/verbal information (Potosky, 2008), in the earliest screening stage. Second, like the job interview, video-résumés are self-reports that enable the applicant to actually tell about knowledge, skills, and abilities to the recruiter instead of merely presenting biographic information such as in paper résumés (Hiemstra et al., 2012). Depending on the degree of construct-oriented formalization (i.e., job requirements), the information 


\section{CHAPTER VIDEO RÉSUMÉS}

exchanged through video résumés resembles more or less that of the traditional job interview (although a-synchronous) compared to the paper résumé. That is, in addition to bio data information, applicants can elucidate their motivation to apply and present relevant skills and knowledge. Typically, this information is tailored to fit a specific job profile.

Yet, despite these two similarities in dynamic information exchange and opportunity to demonstrate one's potential, still notable differences exist between both tools that might affect their validity and fairness. First, both the content and form of video résumés are typically structured by the applicant with a limited amount of time allotted to impress the recruiter, whereas the job interview is typically longer and structured by the recruiter (to a more or lesser extent). Secondly, video résumés are a-synchronous in nature, thereby restricting the real-time two-way interaction/communication exchange between the applicant and the recruiter, whereas face-to-face interviews are synchronous in nature. Finally, and although the length of the job interview may vary considerably, there is typically more opportunity for applicants to adjust their behavior to the particular situation (e.g., what recruiters ask and how they react also in a non-verbal way) compared to video résumés. As a result, video résumés may restrict the amount of personalized/individuating information exchange about candidates as well as subtle impression management and adaptation from the part of the applicant when compared to more traditional face-to-face encounters in the job interview setting (e.g., Bangerter, Roulin, \& König, 2012).

-Table 1 about here -

\section{Review of video résumé research: what we know about video résumés}

Exact numbers on the frequency of use of video résumés in current selection practices is still lacking. A study in 2009 among 176 HR-professionals at medium- and small sized 


\section{CHAPTER VIDEO RÉSUMÉS}

enterprises in the Netherlands showed that $70 \%$ was aware of the existence of video résumés. But only $8 \%$ actually used the video résumé, whereas about $40 \%$ was willing to consider it (Hiemstra, 2013). But, as with traditional résumés, popular media coverage on video résumés in conventional written media sources and on the internet is abundant (Gissel et al., 2013). As described in Gissel et al. (2013), both practitioners and researchers gain interest in video résumés. For instance, in 2012 one of the first symposia on video résumés was organized at the 27th Annual Conference of the Society for Industrial and Organizational Psychology (Derous, Buijsrogge, Gissel, Schmitt, Thompson, Hiemstra, et al., 2012).

Before that date, scholarly publications on the topic were scarce, however, e.g., as indicated by the limited amount of hits (three) on Web of Science after a search in 2012 (Derous, Taveirne, \& Hiemstra, 2012). The three publications in Web of Science furthermore dated from the nineteen eighties and nineties (Hamilton, 1998; Kelly \& O’Brien, 1992; Warshawski, 1987). The publications by Hamilton (1998) and Warshawski (1987) were about dance auditions through videotaped applications. For dancers and musicians it has been common practice for a longer period of time to send in tapes for audition. A recent example is the YouTube orchestra, for which musicians auditioned online by uploading a tape of their performance on YouTube (YouTube Symphonic Orchestra, 2011). Kelly and O’Brien (1992) used the video résumé to teach job search skills to deaf students, helping them to present themselves to potential employers. Light (1993) also described the development of video résumés for persons with disabilities. One of the first scientific publications of video résumés for 'mainstream' applicants seems to stem from 1993 (Rolls \& Strenkowski, 1993), in a pilot among education students. The authors stated that the distribution of video résumés may supply prospective employers with additional nonverbal and interpersonal information that can benefit all stakeholders. 


\section{CHAPTER VIDEO RÉSUMÉS}

More recently, the increased use of internet and social media is starting to find its reflection in recruitment practices (Roth, Bobko, Van Iddekinge, \& Thatcher, 2013; Stoughton, Thompson, \& Meade, 2014), also with video résumés. For instance, in 2009 a worldwide recruitment program was launched by the Queensland Tourist Board in Australia, inviting applicants to send a 60 seconds video message to demonstrate their suitability for a marketing job. An impressive number of 34.000 applicants from around the world responded to this call (Queensland Tourist Board Australia, 2009). More and more examples exist of actual selection procedures in which applicants are invited to apply through a video résumé, both in Europe and in the United States (Hiemstra, Oostrom, Derous, Serlie, \& Born, 2012; Silverman, 2012). Additionally, a growing number of companies are offering services that range from online hosting of video résumés in search databases for recruiters to the full production of résumés for applicants (Gissel et al., 2013).

As developments are moving fast, we conducted a new search of Web of Science and of conference proceedings in December 2013. This resulted in six recent scientific studies that specifically target video résumés (Derous et al., 2012; Gissel et al., 2013; Hiemstra et al., 2012; Hiemstra et al., 2012; Waung, Hymes, Beatty, \& McAuslan, 2012; Waung, Beatty, Hymes, \& McAuslan, 2010). The studies by Gissel et al. (2013) and Hiemstra et al. (2012) focused on the applicants' perspective. Specifically, these authors studied applicants' intentions to apply with a video résumé and applicants' fairness perceptions of video résumés. The studies by Derous et al. (2012) and Waung et al. $(2010 ; 2012)$ focused more on the tool/recruiters' side, namely judgmental accuracy and potential biases. Each of these studies will be discussed here.

Gissel and colleagues (2013) studied video résumés from the applicants' perspective. They researched in a lab-experiment among 154 students why some potential job seekers may 


\section{CHAPTER VIDEO RÉSUMÉS}

choose to submit a video résumé, while others may not. The researchers used Ajzen's (1991) theory of planned behavior as a theoretical framework to assess applicant intentions to apply with a video résumé. The study showed support for the theory of planned behavior in intentions to create a video résumé among entry-level applicants (student participants): A positive attitude toward video résumés, applicants' perceived social pressure to submit video résumés (i.e., social norms), and their self-assessed ability to create/submit video résumés (i.e., perceived behavioral control) all related positively to applicants' intentions to submit video résumés to prospective employers. Attitudes and subjective norms were especially important factors when compared to perceived behavioral control.

Hiemstra et al. (2012) also investigated video résumés from the applicant perspective in a study among 445 unemployed job seekers (both ethnic minorities and majorities) who were enrolled in a subsidized training by the Dutch government, which resulted in a personal video résumé (Hiemstra et al., 2012). In a second study, they investigated 103 higher educated applicants for a legislative traineeship position who were obliged by the hiring organization to submit a videotaped application (Hiemstra et al., 2012). The Hiemstra et al. papers differ from the Gissel et al. (2013) paper in that they assessed actual applicants' fairness perceptions of video résumés, compared to paper résumés. The study among the unemployed job seekers showed that, despite potential discriminatory concerns, ethnic minority applicants perceived the fairness of video résumés equally or more positively when compared to ethnic majority applicants, and when compared to paper résumés. Furthermore, language proficiency was a significant moderator: Higher proficiency of the host country language (Dutch) was related to higher fairness perceptions of paper résumés. The implication was suggested that applicants with a relatively weak labour market position (e.g., those low on host country language skills, ethnic 


\section{CHAPTER VIDEO RÉSUMÉS}

minority applicants) may prefer a more personalized way of applying, (video résumé), instead of less personalized ways (e.g., with paper résumés).

Contrary to the findings among the unemployed job seekers, the highly educated traineeship applicants in the second study (Hiemstra et al., 2012) preferred paper résumés over video résumés in terms of fairness and procedural justice $(1.59<d<2.18)$. This study also explored the role of applicants' personality and cognitive ability in explaining their preferences for paper versus video résumés: Extraverted applicants perceived more opportunity to perform with video résumés compared to introverted applicants. Extraversion was also positively related to face validity perceptions of video résumés. Cognitive ability, on the other hand, related negatively to videotaped application fairness perceptions. The negative finding on cognitive ability pertains to the idea that video résumés may be preferred by applicants with a weaker labor market position (e.g., those with lower GMA or educational level, such as the unemployed job seekers in the Hiemstra et al study).

To summarize, the three available studies on the applicants' perspective showed individual differences in intentions to submit a video résumé, which seemed to be especially related to applicants' attitudes towards video résumés and the perceived social pressure to apply with a video résumé (subjective norm). Also mixed findings in fairness perceptions of video résumés were shown, depending on applicants' ethnicity, language proficiency, cognitive ability, and extraversion.

The other three studies that we found in our search on Web of Science and in conference proceedings were on the equivalence, validity, and the possible discriminating nature of video résumés vis-à-vis paper résumés (Derous et al., 2012; Waung et al., 2012; Waung et al., 2010). 


\section{CHAPTER VIDEO RÉSUMÉS}

Two of those three studies particularly focused on stigmatized applicants: Age and attractiveness were studied by Derous et al. (2012) and gender was studied by Waung et al. (2012).

As regards equivalence, Waung et al. (2010) studied the effect of résumé format on candidate evaluation and résumé outcomes among a group of MBA students. When mock applicants (MBA students) were evaluated based on their video résumés, they were rated as less open, extraverted, physically attractive, socially skilled, and mentally capable, and more neurotic than when the same applicants were evaluated based on their paper résumés. Those who were rated as more socially skilled and more conscientious had a higher probability of positive résumé outcomes. Using two field experiments, Derous et al. (2012) also examined the equivalence of video versus paper résumés on applicants' personality and job suitability ratings, as made by actual recruiters. They concluded that résumé type did not clearly affect applicant ratings. For instance, personality inferences from video résumés appeared as (in) valid as those from paper résumés. As regards the possible discriminating nature of video résumés, applicants'stigma (age, physical attractiveness) was also manipulated in the two field experiments by Derous and colleagues. The results showed that résumé type did moderate the effect of applicants' stigma on personality and job suitability ratings, but that this depended on type of stigma.

Waung and colleagues further investigated the role of gender in video résumé screening (Waung et al., 2012). This was done among students in a laboratory experiment in which applicant gender, and the frequency and intensity of self-promotion statements used in a video résumé were manipulated to examine their effects on applicant evaluation. In this way, differential effects of self-presentation tactics for men and women were hypothesized. It was found that gender role incongruence in the video résumé (i.e., a female using high levels of selfpromotion tactics. Or a male using low levels of self-promotion tactics) resulted in harsher 


\section{CHAPTER VIDEO RÉSUMÉS}

ratings, especially for female applicants compared to male applicants. The female applicant in this study was evaluated more harshly on social skills, credentials, organizational fit, and résumé outcomes when she engaged in high intensity self-promotion compared to low intensity selfpromotion. The male applicant received lower organizational fit and credential ratings when he used lower intensity self-promotion. Notably, these effects were found only when evaluators were male.

The six studies described in this paragraph provide an interesting first insight into the characteristics of video résumés from both the applicants' and recruiters' perspective. Building further on these findings, an agenda for future research is presented next.

\section{Agenda for Future Research: What we want to know about video résumés}

Although the screening of résumés is an ubiquitous procedure in the first selection stage of many hiring organizations, it has received less research attention compared to other selection instruments. This accounts especially for video résumé screening, which has hardly been researched at all. Suggestions for future research can therefore be made that build on the studies described in the previous paragraph. In addition, new areas of research on video résumé screening that were not yet addressed in existing studies can be identified. These topics include research on the validity, reliability, cost-effectiveness, ease of use of paper and video résumés. Furthermore, studies on the fairness of video résumés for a broader array of subgroups (e.g., disabled applicants) and issues regarding privacy and invasiveness deserve our research attention. Each of these topics will be dealt with here and suggestions for future research are be made.

In the 1970s it was already estimated that over one billion résumés were screened each year in the United States. Résumés are usually the first medium through which information is 


\section{CHAPTER VIDEO RÉSUMÉS}

exchanged between the applicant and the hiring organization. The suggestion has been made that biographical information deduced from paper résumés, such as education and work experiences, can be used to draw inferences about underlying attributes, such as personality and intelligence (Brown \& Campion, 1994; Levine \& Flory, 1975). However, the validity in terms of accuracy and added value of this practice compared to other selection instruments is debatable (Cole, Feild, Giles, \& Harris, 2009; Schmidt \& Hunter, 1998), as was also shown in the experiments by Derous et al. (2012). Despite this, résumés are still among the most widely used and best accepted instruments to screen applicants (Anderson, Salgado, \& Hulsheger, 2010; Piotrowski \& Armstrong, 2006). Although some cultural differences have been reported regarding selection

practices (e.g., Huo, Huang, \& Napier, 2002; Ryan, McFarland, Baron, \& Pager, 1999), selection in many countries follows a fairly similar pattern, starting with résumés as a form of prescreening.

Even less is known about the psychometric properties of video résumés. As with preemployment screening through social media (e.g., Stoughton et al., 2014), practitioners often introduce and use new selection tools that are not yet thoroughly investigated by scientist (like the use of social media for recruitment purposes; Roth et al., 2013) or that rather appear to be invalid (like the use of unstructured job interviews for selection purposes; Levanshina et al., 2013). Studies on reasons for this science-practitioner gap are scarce (König, Joeri \& Knuesel, 2011). An interesting exception is a study by König, Klehe, Berchtold, and Kleinmann (2010) among 506 HR professionals. Reasons to adopt selection procedures were assessed by these authors, and the main driver's for choice of selection instruments were applicant perceptions, costs, and diffusion in the field of the selection instrument. Though the predictive validity of selection instruments was deemed important, it only played a modest role in the actual adoption 


\section{CHAPTER VIDEO RÉSUMÉS}

of a selection procedure, as was organizational self-promotion (i.e., using the selection situation to promote one's organization), and perceived legality. Future research may therefore focus on the validity and measurement equivalence of video résumés compared to other commonly used selection instruments. As regards measurement equivalence, video résumés may be too narrow a term, because the instrument does not necessarily imply a literal translation of the paper version to a video version, as is the case with some computerized tests. As was shown in this chapter, characteristics of the interview can be found in the video résumé. Additionally, characteristics of the paper résumé, work sample test, and letters of motivation are also identifiable in the video résumé.

As argued earlier, the reliability and validity of the video résumé can probably be improved in the same way as the reliability and validity of the interview and other selection tools (like the assessment center) can be improved, namely through various way of structuration of the content and the raters' evaluation of the applicant (Campion et al., 1997). Even more so, some factors that can reduce the reliability and validity from interviews, namely unplanned prompting and taking questions from the candidate, are absent in video résumés (Campion et al., 1997), thereby reducing pitfalls associated with real-time interaction.

There is a fair amount of research on the validity of personality and cognitive ability impressions based on interviews (Macan, 2009) and some evidence of impression formation based on paper résumés (Brown \& Campion, 1994; Cole et al., 2009). A video résumé that is created according to the construct requirements of the hiring organization may approach the validity of structured interviews to assess personality, in less time and with more opportunities for multiple raters to review the content (i.e., no real-time panel is needed and all materials remain available online for evaluation per default). Furthermore, research has shown that 


\section{CHAPTER VIDEO RÉSUMÉS}

interviews are stressors and applicant anxiety can impair the validity of interview ratings (Macan, 2009; McCarthy \& Goffin, 2004). Applicant training and coaching can improve the applicants' performance and thereby improve the validity of the interview. The good thing about video résumés is that both anxiety and training can be controlled. If an applicant knows his/her strong points and knows how to present them (i.e., the desired result of applicant training and coaching), without the anxiety that is associated to the typical selection situation, it can be implied that video résumés actually may allow for a more accurate person evaluation than the traditional face-to-face interview. Of course, these implications need to be tested using a rigorous construct-oriented approach.

As regards the cost effectiveness and ease of use, some practitioners mention that it may be very time-consuming to screen video résumé, especially when compared to paper résumés. We are not aware of automated coding software, as is the case for paper résumés. Hence, further research is needed on this issue. On the other hand, if video résumé screening ensures more effective selection in the first round (i.e., improved predictive validity), it's use may be more cost-effective in terms of reduced interview time. Of the participants from the survey on video résumé use in the Netherlands (Hiemstra, 2013), about 43 percent thought that the use of video résumés could actually speed up the selection process. For instance, video résumés would allow to quickly assess the representativeness of the applicant before inviting him or her to the job interview. One HR manager that used video résumés in the selection procedure stated that he preferred spending a few more minutes on screening video résumés, in order not to invite ' false positives' to the interview based on screening paper résumés only. Cost effectiveness probably also depends on the size of the applicant pool and the selection ratio. We hypothesize a curvilinear effect here. That is, when the applicant pool is small and the selection ratio is high, 


\section{CHAPTER VIDEO RÉSUMÉS}

most applicants will be invited for an interview, thereby limiting the added value of a video résumé in addition to the traditional paper résumé. The tradeoff may be better when the selection ratio is low and the number of applicants is higher but still manageable. Recruitment campaigns that result in thousands of applicants, on the other hand, may be more effective when using automated screening of the paper résumé in the first phase. The video résumés of those selected based on the automatic screening can then be viewed. In this way, the paper résumé is the first hurdle and the video résumé the second hurdle in the pre-screening of applicants because viewing all individual video résumés in the first place may not be cost effective. Cost effectiveness may also be higher in global recruitment, when opportunities for face-to-face interactions are limited due to time and distance. Future research may address these claims. Caution is warranted though, because the above claims on cost effectiveness are based on adding video résumés to current, mainstream selection practices (i.e., starting the procedure with résumé screening). The practice of résumé screening itself, in terms of predictive validity, is despite its widespread use still debatable compared to other selection instruments, such as cognitive ability tests.

The ease of use of multimedia in selection has increased drastically the past few years, for both recruiters and applicants. Technological developments and software allow for webbased interviews, as well as video résumé creation, sending and online hosting. As for the applicants, they may find it more convenient and up-to-date to use a video based application instead of, or in addition to, a paper based application (i.e., application form, paper résumé, motivational letter). End user software and webcams are now readily available to all users of internet, making the creation and sending of a video résumé accessible to most applicants. Some authors warn for an increased ' digital divide' (Roth et al., 2013), pointing out the trend of less 


\section{CHAPTER VIDEO RÉSUMÉS}

computer/Internet access for Blacks and Hispanics, and the trend for lack of use of social media by older individuals. This may raise possible differences between various groups on the basis of possibilities and ability (or interest) to create and send an online video message. Thus, the ease of use may differ per subgroup of applicants, which also taps into fairness issues.

As regards fairness and justice, future research could build on the studies that were already published to be able to disentangle the influence of the format (e.g., a highly structured, predefined format with content requirements vs. an unstructured format in which the content is determined by the applicant), the medium (paper vs. video vs. interview), and individual differences (e.g., educational level, ethnicity, personality) on applicant and recruiter perceptions. The role of ethnicity, gender, attractiveness and age was considered in both lab and field experiments, yielding some mixed findings. More research is needed among actual applicants and actual recruiters. Moreover, the role of other stigma's, such as religious attire, disabilities and disfigurements can be studied (e.g., Madera \& Hebl, 2012). Another question is whether the results from the interview literature on the role that stigma play in recruiters' judgments and decision making can be transferred to video résumés. As mentioned, video résumés and interviews share several characteristics, yet they are also distinct on several key features (e.g., synchronicity, duration, opportunities for impression management). The studies by Waung et al. and Derous et al., showed a differential effect for different kind of stigma that may be associated to the kind of stereotypes that are associated to the stigma. More research is needed to disentangle the influence of medium (video résumé / paper résumé / interview) and type of stigma on impression formation and hiring decision making.

In addition to research on stigma and stereotypes as a source of judgmental bias, future research may also focus on impression formation and biases due to auditory factors in personnel 


\section{CHAPTER VIDEO RÉSUMÉS}

selection. Auditory information covaries with visual information in both video résumés and interviews. Effects of auditory information on hiring decisions remained relatively under researched until now (Gluszek \& Dovidio, 2010). Among these auditory factors are vocal cues like voice pitch (DeGroot \& Motowidlo, 1999), recruiters' language attitudes, and their relation with perceived accent understandability. These attitudes turned out to be related to job suitability ratings for interviews (De Groot \& Kluemper, 2007; Purkiss, Perrewé, Gillespie, Mayes, \& Ferris, 2006). Future research may also focus on contextual conditions under which it is beneficial to apply with a video résumé and/or a paper résumé. For example, differences in impression formation may occur for types of occupations for which different job qualifications are required (e.g., a marketing versus an administrative position), or for different job types (e.g., a back office versus front office position).

Finally, with the emergence of video résumés and other internet-based technologies, issues arise on privacy (compared to paper résumés). An infamous example of privacy breach is the video résumé application of a student who applied with a video résumé but the content did not match the corporate standards of the hiring organization (De la Merced, 2006). An employee forwarded the application to other recruiters, who put it on the internet. The clip went viral and was parodied (Cera, 2006). The video résumé became famous, thereby making the applicant infamous. Thus, the increased social cue exchange in video résumés when compared to the 'paper person' in paper résumés, the digital and asynchronous nature of video résumés, and the lack of standardization of video résumé requirements may result in higher invasiveness and privacy intrusions for video résumé applications compared to traditional written applications and to face-to-face interviews. This may have negative consequences for the applicant in a particular selection procedure, but also for his or her future applications as was the case with the student in 


\section{CHAPTER VIDEO RÉSUMÉS}

the example, because the video résumé remained visible on the internet. Future research may focus on privacy issues in video résumé screening, and more broadly on the use of social media in selection (Roth et al., 2013).

\section{Conclusion}

In this chapter we have introduced the video résumé as a relatively new instrument that is being used for the early screening of job applicants. Though popular media coverage on video résumés is abundant, research on the topic is still scarce. Because the notion of 'video résumé' might still be unclear, we started this chapter with comparing video résumés to job interviews, being another widely used selection instrument.

Like with any selection tool, video résumés have benefits and disadvantages too. We believe that video résumés may potentially be used for selection if the measurements intentions are clearly defined. Furthermore, video résumés can be considered when it is desirable to provide applicants a more personalized opportunity to apply, thereby appealing more to those with a weaker labor market position, as well as to more extraverted applicants. At the same time the workplace in Western countries is rapidly becoming more diverse and differential job access persists. Video résumés also have the potential to instigate discriminatory hiring practices, therefore caution is also warranted when using video résumés. The growing use of multimedia instruments for selection, such as video résumés, needs to continuously be scrutinized, in research and in the field, to ensure fair and accurate application and evaluation procedures. We hope this chapter adds to this goal. 


\section{CHAPTER VIDEO RÉSUMÉS}

\section{References}

Ajzen, I. (1991). The theory of planned behavior. Organizational Behavior and Human Decision Processes, 50, 179-211. doi: http://dx.doi.org/10.1016/0749-5978(91)90020-T

Anderson, N., Salgado, J., \& Hulsheger, U. R., (2010). Applicant reactions in selection: Comprehensive meta-analysis into reaction generalization versus situational specificity. International Journal of Selection and Assessment, 18, 291-304. doi: 10.1111/j.14682389.2010.00512.x

Arthur, W., \& Villado, A. J. (2008). The importance of distinguishing between constructs and methods when comparing predictors in personnel selection research and practice. Journal of Applied Psychology, 93, 435-442. doi:10.1037/0021-9010.93.2.435

Bangerter, A., Roulin, N., \& König, C. J. (2012). Personnel selection as a signaling game. Journal of Applied Psychology, 97, 719-738. doi:10.1037/a0026078

Bauer, T. N., Truxillo, D. M., Paronto, M. E., Weekley, J. A., \& Campion, M. A. (2004). Applicant reactions to different selection technology: Face-to-face, interactive voice response, and computer-assisted telephone screening interviews. International Journal of Selection and Assessment, 12, 135-148. doi: 10.1111/j.0965-075X.2004.00269.x

Brown, B. K., \& Campion, M. A. (1994). Bio data phenomenology - recruiters perceptions and use of biographical information in résumé screening. Journal of Applied Psychology, 79, 897-908. doi: 10.1037/0021-9010.79.6.897 


\section{CHAPTER VIDEO RÉSUMÉS}

Campion, M. A., Palmer, D. K., \& Campion, J. E. (1997). A review of structure in the selection interview. Personnel Psychology, 50, 655-702. doi:10.1111/j.17446570.1997.tb00709.x

Cera, M. (2006, 20 December). Impossible is the opposite of possible. Retrieved from http://www.youtube.com/watch?v=nAV0sxwx9rY.

Cole, M. S., Feild, H. S., Giles, W. F., \& Harris, S. G. (2009). Recruiters' inferences of applicant personality based on résumé screening: Do paper people have a personality? Journal of Business and Psychology, 24, 5-18. doi:10.1007/s10869-008-9086-9

Cole, M. S., Rubin, R. S., Feild, H. S., \& Giles, W. F. (2007). Recruiters' perceptions and use of applicant résumé information: Screening the recent graduate. Applied Psychology: An International Review, 56, 319-343. doi:10.1111/j.1464-0597.2007.00288.x

Cook, M. (2009). Personnel selection: Adding value through people. Chichester: Wiley.

DeGroot, T., \& Kluemper, D. (2007). Evidence of predictive and incremental validity of personality factors, vocal attractiveness and the situational interview. International Journal of Selection and Assessment, 15, 30-39. doi:10.1111/j.1468-2389.2007.00365.x

DeGroot, T, Motowidlo, S. J. (1999). Why visual and vocal interview cues can affect interviewers' judgments and predict job performance. Journal of Applied Psychology, 84, 986-993. doi: $\underline{10.1037 / 0021-9010.84 .6 .986}$ 


\section{CHAPTER VIDEO RÉSUMÉS}

De la Merced, M. J. (2006, 19 October). The résumé mocked around the world. The New York Times Deal book. Retrieved from http://dealbook.blogs.nytimes.com/2006/10/19/therésumé-mocked-round-the-world-vayner-speaks/.

Derous, E., Buijsrogge, A., Gissel, A., Schmitt, N., Thompson, L., Hiemstra, A. M. F., et al. (2012, April). Differential effects of video versus paper résumés on personality ratings. In E. Derous (Chair),Assessing Video Résumés: Valuable and/or Vulnerable to Biased Decision Making? Symposium conducted at the annual meeting of the Society for Industrial and Organization Psychology, San Diego, CA.

Derous, E., Taveirne, A., \& Hiemstra, A.M.F., (2012, April). Résumé-Résumé On The VideoWall: Who's The Most Hirable Of All? Interactive poster presented at the $27^{\text {th }}$ Annual Conference of the Society for Industrial and Organizational Psychology, San Diego, CA.

Dipboye, R. L., \& Johnson, S. K. (2013). Understanding and improving employee selection interviews. In K. F. Geisinger, B. A. Bracken, J. F. Carlson, J.-I. C. Hansen, N. R. Kuncel, S. P. Reise \& M. C. Rodriguez (Eds.), (pp. 479-499). Washington, DC, US: American Psychological Association. doi:10.1037/14047-027

Doyle, A. (2010). Video Résumé - Video Résumés for Job Seekers. Retrieved from http://jobsearch.about.com/od/résumés/g/videorésumé.htm.

Gissel, A. L., Thompson, L. F., \& Pond, S. B. (2013). A theory-driven investigation of prospective applicants' intentions to submit video résumés. Journal of Applied Social Psychology, 43(12), 2449-2461. doi:10.1111/jasp.12191 


\section{CHAPTER VIDEO RÉSUMÉS}

Gluszek, A., \& Dovidio, J. F. (2010). Speaking with a nonnative accent: Perceptions of bias, communication difficulties, and belonging in the united states. Journal of Language and Social Psychology, 29(2), 224-234. doi:10.1177/0261927X09359590

Guion, R.M. (2011). Assessment, Measurement and Prediction for Personnel Decisions. Second Edition. New York: Lawrence Erlbaum.

Hamilton, L. (1998). Your first move - how to prepare a winning audition package (the dance résumé, photos and video). Dance Magazine, 72(2), 140.

Hiemstra, A.M.F. (2013). Fairness in Paper and Video Résumé Screening. (Doctoral Dissertation). Ridderkerk, the Netherlands: Ridderprint B.V.

Hiemstra, A. M. F., Derous, E., Serlie, A. W., \& Born, M. Ph. (2012). Fairness perceptions of video résumés among ethnically diverse applicants. International Journal of Selection and Assessment, 20, 423-433. doi:10.1111/ijsa.12005

Hiemstra, A.M.F., Oostrom, J. K., Derous, E., Serlie, A. W., \& Born, M. Ph. (2012, July). Video and Paper Résumés: Exploring Applicants' Preferences Based on Personality and Cognitive Ability. Paper presented at the $8^{\text {th }}$ conference of the International Test Commission (ITC), Amsterdam, the Netherlands.

Huo, Y., Huang, H., \& Napier, N. (2002). Divergence or convergence: A cross-national comparison of personnel selection practices. Human Resource Management, 41, 31-44. doi:10.1002/hrm.10018 


\section{CHAPTER VIDEO RÉSUMÉS}

Kelly, J., \& O'Brien, E. (1992). Using video résumés to teach deaf college-students job search skills and improve their communication. American Annals of the Deaf, 137, 404-410. Retrieved from http://gupress.gallaudet.edu/annals/92volume.htm

König, C. J., Joeri, E., \& Knuesel, P. (2011). The amazing diversity of thought: A qualitative study on how human resource practitioners perceive selection procedures. Journal of Business and Psychology, 26, 437-452. doi:10.1007/s10869-010-9199-9

König, C. J., Klehe, U., Berchtold, M., \& Kleinmann, M. (2010). Reasons for being selective when choosing personnel selection procedures. International Journal of Selection and Assessment, 18, 17-27. doi: 10.1111/j.1468-2389.2010.00485.x

Levashina, J., Hartwell, C. J., Morgeson, F. P., \& Campion, M. A. (2013). The structured employment interview: Narrative and quantitative review of the research literature. Personnel Psychology. Advance online publication. doi: 10.1111/peps.12052

Levine, E., \& Flory, A. (1975). Evaluation of job applications - conceptual framework. Public Personnel Management, 4(6), 378-385.

Lievens, F. (2011). Handbook Human Resource Management. Leuven, Belgium: Lannoo Campus.

Light, L. (1993). Video résumé: An application of technology for persons with severe disabilities. Retrieved from ERIC database. (EJ459595). 


\section{CHAPTER VIDEO RÉSUMÉS}

Macan, T. (2009). The employment interview: A review of current studies and directions for future research. Human Resource Management Review, 19(3), 203-218. doi: http://dx.doi.org/10.1016/j.hrmr.2009.03.006

Madera, J. M., \& Hebl, M. R. (2012). Discrimination against facially stigmatized applicants in interviews: An eye-tracking and face-to-face investigation. Journal of Applied Psychology, 97, 317-330. doi:10.1037/a0025799

McCarthy, J., \& Goffin, R. (2004). Measuring job interview anxiety: Beyond weak knees and sweaty palms. Personnel Psychology, 57, 607-637. doi:10.1111/j.17446570.2004.00002.x

Oostrom, J. K. (2010). New technology in personnel selection: The validity and acceptability of multimedia tests. (Doctoral dissertation). Retrieved from http://repub.eur.nl/res/pub/20866/

Piotrowski, C., \& Armstrong, T. (2006). Current recruitment and selection practices: A national survey of Fortune 1000 firms. North American Journal of Psychology, 8, 489496. Retrieved from http://web.ebscohost.com/ehost

Potosky, D. (2008). A conceptual framework for the role of the administration medium in the personnel assessment process. Academy of Management Review, 33, 629-648. doi: http://www.jstor.org/stable/20159428

Purkiss, S. L. S., Perrewé, P. L., Gillespie, T. L., Mayes, B. T., \& Ferris, G. R. (2006). Implicit sources of bias in employment interview judgments and decisions. 


\section{CHAPTER VIDEO RÉSUMÉS}

Organizational Behavior and Human Decision Processes, 101, 152-167.

doi:10.1016/j.obhdp.2006.06.005

Queensland Tourist Board Australia (2009). About the best job. Retrieved 3 December 2009 from: http://islandreefjob.com/about-the-best-job/.

Rolls, J.A. \& Strenkowski, R.A. (1993, Aug). Video technology: Résumés of the future. Retrieved from ERIC database. (ED362934).

Roth, P. L., Bobko, P., Van Iddekinge, C. H., \& Thatcher, J. B. (2013). Social media in employee-selection-related decisions: A research agenda for uncharted territory. Journal of Management. Advance online publication. doi:10.1177/0149206313503018

Ryan, A. M., McFarland, L., Baron, H., \& Page, R. (1999). An international look at selection practices: Nation and culture as explanations for variability in practice. Personnel Psychology, 52, 359-391. doi:10.1111/j.1744-6570.1999.tb00165.x

Sands, W. A., Waters, B.K., \& McBride, J. R. (Eds.) (1997). Computerized adaptive testing: From inquiry to operation. Washington, DC: American Psychological Association.

Schmidt, F. L., \& Hunter, J. E. (1998). The validity and utility of selection methods in personnel psychology: Practical and theoretical implications of 85 years of research findings. Psychological Bulletin, 124, 262-274. doi: 10.1037/0033-2909.124.2.262

Silverman, R. E. (2012, January 24). No more résumés, say some firms. Wall Street Journal. Retrieved from: http://online.wsj.com 


\section{CHAPTER VIDEO RÉSUMÉS}

Stoughton, J. W., Thompson, L. F., Meade, A. W. (2013). Examining applicant reactions to the use of social networking websites in pre-employment screening. Journal of Business and Psychology. Advance online publication. doi10.1007/s10869-013-9333-6

Warshawski, E. (1987). Video résumés, sharpening the competitive edge for dancers, choreographers and dance-companies. Dance Magazine, 61(3), 40-41.

Waung, M., Beatty, J., Hymes, R., \& McAuslan, P. (2010, April). The Effects of Video and Paper Résumés on Candidate Evaluation. Poster presented at the $25^{\text {th }}$ Annual Conference of the Society for Industrial and Organizational Psychology, Atlanta, GA

Waung, M., Hymes, R., Beatty, J., \& McAuslan, P. (2012, April). Video résumé self promotion tactics and gender. In E. Derous (chair), Assessing Video Résumés: Valuable and/or Vulnerable to Biased Decision-making? Symposium conducted at the at the $27^{\text {th }}$ Annual Conference of the Society for Industrial and Organizational Psychology, San Diego, CA.

YouTube Symphonic Orchestra (2011). 101 musicians from 33 countries: Selected on YouTube. Retrieved from http://www.youtube.com/user/symphony 
Table 1

Comparison of Two Selection Media: Video Résumé versus Job Interview

\begin{tabular}{|c|c|c|c|}
\hline \multicolumn{2}{|c|}{ Features of both Media } & \multirow{2}{*}{$\begin{array}{l}\text { Video résumé } \\
\text { Background information and } \\
\text { KSAOs: past-oriented (e.g., } \\
\text { biographic information) and } \\
\text { present-oriented (e.g., } \\
\text { demonstrating skills) }\end{array}$} & \multirow[b]{2}{*}{$\begin{array}{l}\text { Job interview } \\
\text { Background information and } \\
\text { KSAOs: past-oriented (e.g., } \\
\text { biodata; behavior description } \\
\text { interview), present-oriented (e.g., } \\
\text { skills demonstrated in the interview } \\
\text { like in performance interviews), } \\
\text { and future oriented (e.g., } \\
\text { situational and hypothetical } \\
\text { questions) }\end{array}$} \\
\hline Content & Type of information that is exchanged & & \\
\hline Format & $\begin{array}{l}\text { Format characteristics including the } \\
\text { communication code (verbal vs. non- } \\
\text { verbal), the administration duration, } \\
\text { the number of actors involved, the } \\
\text { direction of communication (one-way } \\
\text { vs. two-way) the degree of surveillance } \\
\text { (actual security/invasiveness) }\end{array}$ & $\begin{array}{l}\text { Spoken résumés that include both } \\
\text { verbal and non-verbal } \\
\text { information; short duration } \\
\text { (typically less than } 2 \text { minutes), } \\
\text { only one actor (applicant) } \\
\text { involved, surveillance can vary } \\
\text { from very low to high }\end{array}$ & $\begin{array}{l}\text { Verbal and non-verbal } \\
\text { communication, with varying } \\
\text { duration from short till very long, } \\
\text { two or more actors involved (one } \\
\text { applicant and one of more } \\
\text { recruiters), and typically high } \\
\text { surveillance }\end{array}$ \\
\hline Standardization & $\begin{array}{l}\text { Degree of standardization, i.e., whether } \\
\text { standardized procedures are } \\
\text { maintained or not across all applicants }\end{array}$ & $\begin{array}{l}\text { Standardization fluctuates } \\
\text { depending on the recruiters' } \\
\text { policy (e.g., whether they request }\end{array}$ & $\begin{array}{l}\text { Typically, interviews are } \\
\text { standardized across applicants (not } \\
\text { necessarily across procedures) }\end{array}$ \\
\hline
\end{tabular}


CHAPTER VIDEO RÉSUMÉS

\begin{tabular}{|c|c|c|c|}
\hline & and tests & $\begin{array}{l}\text { all applicants to send-in a video } \\
\text { résumé or not) }\end{array}$ & \\
\hline Structuration & $\begin{array}{l}\text { Degree of structuration, i.e., whether } \\
\text { the tool is tailored to fit the work to be } \\
\text { done, by whom structuration takes } \\
\text { place, and whether a scoring protocol is } \\
\text { used }\end{array}$ & $\begin{array}{l}\text { Mostly structured by the } \\
\text { applicant, but can also be } \\
\text { structured by the recruiter. The } \\
\text { video résumé can be tailored to fit } \\
\text { the work to be done in several } \\
\text { degrees. The video résumé can be } \\
\text { scored according to a protocol. }\end{array}$ & $\begin{array}{l}\text { Mostly structured by the recruiter } \\
\text { (structured). The interview } \\
\text { structure (including rating scales) } \\
\text { varies widely from individualized } \\
\text { structured interviews till } \\
\text { comprehensive structured } \\
\text { interviews. }\end{array}$ \\
\hline Administration medium & $\begin{array}{l}\text { Whether the information carrier is } \\
\text { analogue or digital in nature }\end{array}$ & Digital (i.e., web-based) & $\begin{array}{l}\text { Analogue (e.g., face-to-face } \\
\text { interviews) and digital (e.g., web- } \\
\text { based interviewing and } \\
\text { videoconference interviews) }\end{array}$ \\
\hline Interactivity & $\begin{array}{l}\text { The extent to which the tool allows } \\
\text { for reciprocal information exchange } \\
\text { (i.e., turn taking) and relatedly } \\
\text { whether the information exchange is } \\
\text { asynchronous or synchronous in } \\
\text { nature }\end{array}$ & One-way directed, a-synchronous & Two-way directed, synchronous \\
\hline
\end{tabular}

